\title{
Increase in Air Accompanying Flour Particles due to Flour Treatments
}

\author{
Yoko ShimiY A* and Toshimasa YANo \\ Department of Agricultural Chemistry, The University of Tokyo, \\ Bunkyo-ku, Tokyo 113, Japan
}

Received July 25, 1986

\begin{abstract}
The effects of sifting, drying, lipid extraction, oxidation with benzoyl peroxide and aging on the amounts of air accompanying particles of weak and strong wheat flours and a rice flour were investigated. The drying and the lipid extraction were effective in increasing the amount of accompanying air, and the combination of drying and lipid extraction was the most effective. The additional accompanying air due to these treatments was found to be held in a space larger than $30 \mathrm{~nm}$ in diameter inside the flour particles. The increase in air accompanying flour particles may improve the characteristics of flours used in baking and extrusion cooking.
\end{abstract}

Wheat flour used in baking is subjected to various treatments after milling in order to improve its baking characteristics. The effects of flour treatments have been studied by many workers, including chlorine treatment, ${ }^{1 \sim 3)}$ ascorbic acid treatment, ${ }^{4)}$ temperature and humidity control, ${ }^{5,6)}$ addition of $\mathrm{NaCl}^{7,8)}$ aging, ${ }^{9,10)} \gamma$-ray irradiation, ${ }^{11)}$ and lipid extraction and reconstitution. ${ }^{12 \sim 14)}$ Unfortunately most of these studies were qualitative, evaluating the treatments as to the loaf volume and appearance of the final products. In the preceding study, ${ }^{15)}$ the amount of air accompanying flour particles was measured for a weak wheat flour, a strong wheat flour and a rice flour. The results showed that the amount of air accompanying the wheat flour particles was larger than that accompanying the rice flour particles, which suggested a certain role of the accompanying air in the expansion of flour doughs. In this study, increases in the air accompanying flour particles were investigated on applying such treatments as sifting, dring, lipid extraction, oxidation and aging to the flours.

\section{MATERIALS AND METHODS}

Flours. Commercially available strong and weak wheat fluors and a rice flour were classified by sifting, and a fraction of the flour particles between 74 and $125 \mu \mathrm{m}$ in diameter was used. The approximate chemical compositions of the flours were given in the preceding paper. ${ }^{15}$ ) All the samples were preserved at $20^{\circ} \mathrm{C}$ and $58 \%$ relative humidity. For the aging experiments, grains of No. 1 Canada Western Red Spring wheat (No. $1 \mathrm{CW}$ wheat) and grains of non-glutinous rice were milled just before the experiments.

Drying. Sample flours were placed over saturated salt solutions to control their moisture contents. The saturated salt solutions used and the corresponding relative humidities were $\mathrm{NaBr} \cdot 2 \mathrm{H}_{2} \mathrm{O}: 58 \%, \quad \mathrm{~K}_{2} \mathrm{CO}_{3} \cdot 2 \mathrm{H}_{2} \mathrm{O}: 44 \%$, $\mathrm{CH}_{3} \mathrm{COOK} \cdot 1.5 \mathrm{H}_{2} \mathrm{O}: 23 \%, \mathrm{LiCl} \cdot \mathrm{H}_{2} \mathrm{O}: 12 \%$, and $\mathrm{P}_{2} \mathrm{O}_{5}$ : zero $\%{ }^{16}$ ) The moisture conditioning was accelerated under reduced pressure. ${ }^{17)}$ It took about 20 days for the flours to reach the equilibrium state. The moisture contents of the conditioned flours were determined gravimetrically by drying the samples at $105^{\circ} \mathrm{C}$ for $5 \mathrm{hr}$.

Lipid extraction. Lipid extraction with ethyl ether was carried out at $50^{\circ} \mathrm{C}$ for $16 \mathrm{hr}$ using a Soxhlet extractor. Ethyl ether affects other flour components very little. ${ }^{18)}$ The extracted flours were first dried under a flow of air, and were then left overnight at about $50^{\circ} \mathrm{C}$ for complete evaporation of the ethyl ether.

Reconstitution of lipid. According to Seguchi et al., ${ }^{19)} \mathrm{a}$ 
particular lipid was dissolved in ethyl ether and then mixed well with the lipid-extracted flours. Then ethyl ether was evaporated by the above -mentioned procedure.

Oxidation. Sample flours were mixed with $0.1 \sim 10 \%$ of benzoyl peroxide powder and then left for about 5 days at $20^{\circ} \mathrm{C}$ and $58 \%$ relative humidity. Oxidation by benzoyl peroxide occurs through the following reaction. ${ }^{20}$ )

$$
\left(\mathrm{C}_{6} \mathrm{H}_{5} \mathrm{CO}\right)_{2} \mathrm{O}_{2}+\mathrm{H}_{2} \mathrm{O}=2 \mathrm{C}_{6} \mathrm{H}_{5} \mathrm{COOH}+\mathrm{O}
$$

Aging. Fresh milled flours of No. $1 \mathrm{CW}$ wheat and non-glutinous rice were aged for 32 days at $20^{\circ} \mathrm{C}$. The No. 1 $\mathrm{CW}$ wheat flour was also aged under reduced pressure of $20 \mathrm{mmHg}$ for comparison.

The specific volume of air accompanying flour particles. As described in the preceding paper, ${ }^{15}$ ! the volume of air accompanying flour particles was determined through measurement of the apparent densities of the flour particles with and without accompanying air in water.

Nitrogen adsorption isotherm. A sample was dehydrated over $\mathrm{P}_{2} \mathrm{O}_{5}$ under vacuum. The nitrogen adsorption isotherm of the sample was measured with an Accusorb 210001 (Shimadzu Seisakujo) as described in the preceding paper. $^{15)}$

Specific pore volume distribution. This was calculated from the nitrogen adsorption isotherm using the Cranston-Inkley method. ${ }^{15)}$

\section{RESULTS}

Table I summarizes the increases in air accompanying flour particles due to the flour treatments.

\section{1) Effect of sifting on the accompanying air}

The moisture content of strong wheat flour B decreased from 0.150 to $0.132 \mathrm{~kg} / \mathrm{kg}$ dry matter during sifting for $1 \mathrm{hr}$. The specific volume of the accompanying air increased with the sifting from 10.0 to $12.8 \mathrm{~cm}^{3} / \mathrm{kg}$ dry matter for the strong wheat flour $\mathrm{B}$ and from 8.3 to $10.4 \mathrm{~cm}^{3} / \mathrm{kg}$ dry matter for the rice flour $\mathrm{D}$, as shown in Table I. When the sifted flours were suspended in water, the time courses of the change in the amount of accompanying air were parallel to the original one, as Fig. 1 shows. The amount of accompanying air decreased rather rapidly but still the initial increase in the accompanying air remained
TABle I. InCreases IN AIR ACCOMPANYing Flour Particles Due to Flour Treatments

\begin{tabular}{|c|c|c|c|c|c|}
\hline \multirow{3}{*}{$\begin{array}{l}\text { Flour } \\
\text { treatment }\end{array}$} & \multicolumn{5}{|c|}{$\begin{array}{l}\text { Specific volume of air accompanying } \\
\text { flour particles }\left[\mathrm{cm}^{3} / \mathrm{kg}-\mathrm{D} . \mathrm{M} .\right]\end{array}$} \\
\hline & \multirow{2}{*}{$\begin{array}{c}\text { Weak } \\
\text { wheat } \\
\text { flour }\end{array}$} & \multicolumn{2}{|c|}{$\begin{array}{c}\text { Strong } \\
\text { wheat } \\
\text { flour }\end{array}$} & \multicolumn{2}{|c|}{$\begin{array}{l}\text { Rice } \\
\text { flour }\end{array}$} \\
\hline & & A & B & $\mathrm{C}$ & $\mathrm{D}^{b}$ \\
\hline Original flour & 15.0 & 11.3 & 10.0 & 0.9 & 8.3 \\
\hline Sifting & - & - & 12.8 & - & 10.4 \\
\hline Drying $^{a}$ & 32.0 & 29.0 & - & 10.3 & - \\
\hline Lipid extraction & - & - & 26.5 & - & 19.3 \\
\hline $\begin{array}{l}\text { Lipid reconsti- } \\
\text { tution }\end{array}$ & - & - & - & - & $\begin{array}{r}5.9 \\
\sim 9.3\end{array}$ \\
\hline $\begin{array}{l}\text { Lipid extraction } \\
\text { and drying }\end{array}$ & - & 98.5 & - & - & - \\
\hline $\begin{array}{l}\text { Oxidation with } 1 \% \\
\text { Benzoyl peroxide }\end{array}$ & 19.0 & 14.2 & - & 4.2 & - \\
\hline
\end{tabular}

a The moisture contents of the flours were nearly zero.

$b$ Rice flour preserved for several months.

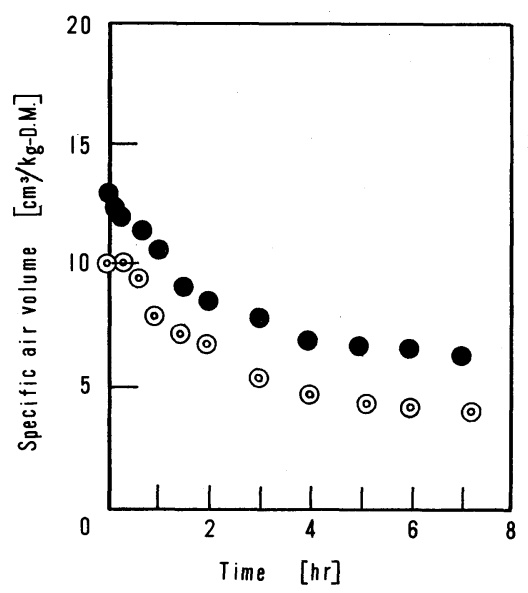

FIG. 1. Effect of Sifting on the Specific Air Volume of Strong Wheat Flour B Suspended in Water $\left(d_{\mathrm{p}}=74 \sim 125 \mu \mathrm{m}\right)$.

(O), before sifting; 0 , after sifting. D.M.: dry matter; $d_{\mathrm{p}}$ : diameter of flour particles.

advantageous.

\section{2) Effect of drying}

Figure 2 shows how the specific volume of air accompanying flours increased as the moisture content of the flours decreased. As report- 


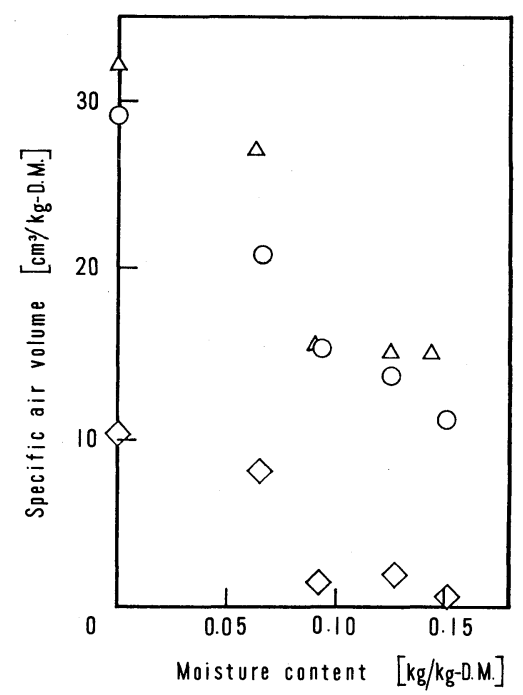

FIG. 2. Effect of Moisture Content on the Specific Air Volume of Flours Suspended in Water $\left(d_{\mathrm{p}}=74 \sim 125 \mu \mathrm{m}\right)$. $\bigcirc$, strong wheat flour A; $\triangle$, weak wheat flour; $\diamond$, rice flour C.

ed in the preceding paper, ${ }^{15)}$ the specific volumes of micropores less than $30 \mathrm{~nm}$ in diameter were $1.93 \mathrm{~cm}^{3} / \mathrm{kg}$ dry matter for the dry weak wheat flour, $0.96 \mathrm{~cm}^{3} /$ dry matter for the dry strong wheat flour and $0.74 \mathrm{~cm}^{3} / \mathrm{kg}$ dry matter for the dry rice flour. Comparing these values with the data in Fig. 2, it can be seen that most of the additional air was held in a space larger than $30 \mathrm{~nm}$ in diameter inside the flour particles. The accompanying air was rather stable in water, although the results are not shown here to avoid repetition.

\section{3) Effects of lipid extraction and reconstitu- tion}

On lipid extraction, as Table I and Fig. 3 show, the amount of accompanying air not only increased significantly but also became stable in aqueous suspensions of the flours. As Fig. 4 shows, the specific volume distribution of micropores of the strong wheat flour, less than $30 \mathrm{~nm}$ in diameter, was also changed by the lipid extraction, the total volume of micropores increasing from 0.96 to $2.18 \mathrm{~cm}^{3} / \mathrm{kg}$ dry matter. Since the increase in micropores was less than the total increase in accompany-

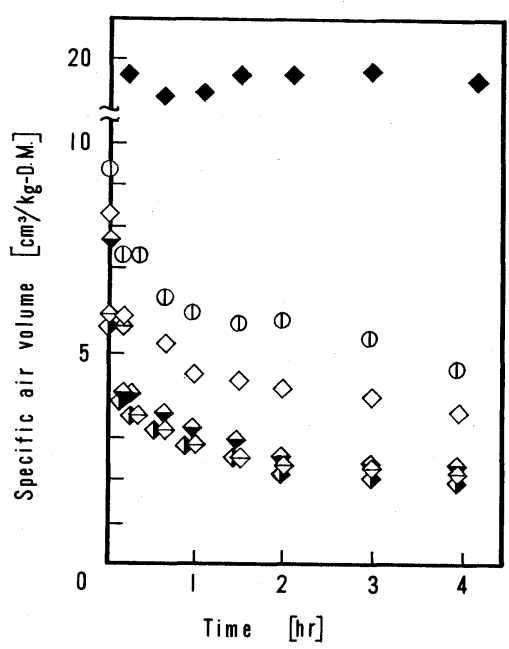

FIG. 3. Effects of Lipid Extraction and Lipid Reconstitution on the Specific Air Volume of Rice Flour $\left(d_{\mathrm{p}}=74 \sim 125 \mu \mathrm{m}\right)$.

$\diamond$, rice flour $\mathrm{D}$; $\diamond$, lipid extracted rice flour $\mathrm{D}$; $\diamond, \quad 0.0042 \mathrm{~kg} / \mathrm{kg}-$ D.M., $\diamond, \quad 0.0084 \mathrm{~kg} / \mathrm{kg}$-D.M., $0.0168 \mathrm{~kg} / \mathrm{kg}-\mathrm{D} . \mathrm{M}$., reconstituted with rice lipid; (1), $0.0086 \mathrm{~kg} / \mathrm{kg}-$ D.M., reconstituted with wheat lipid.

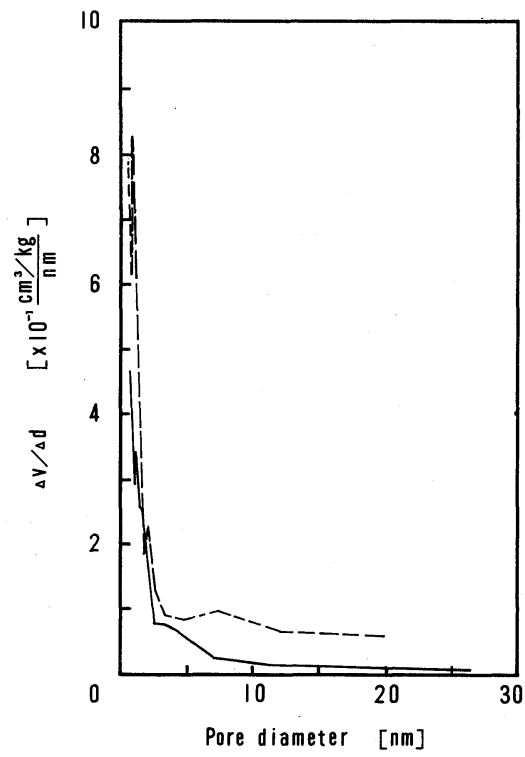

FIG. 4. Pore Volume Distribution Curves for Lipid Extracted Strong Wheat Flour A $\left(d_{\mathrm{p}}=74 \sim 125 \mu \mathrm{m}\right)$.

wheat flour A. $\Delta v / \Delta d$, pore volume differentiated with pore diameter.

ing air due to lipid extraction shown in Table I, most of the additional accompanying air due to the lipid extraction was again held in a space 
larger than $30 \mathrm{~nm}$ in diameter. The increases in accompanying air due to lipid extraction shown in Table I were larger than the volumes of the removed lipids, which were about $11 \mathrm{~cm}^{3}$ of lipid per $\mathrm{kg}$ of the strong wheat flour and about $4.4 \mathrm{~cm}^{3}$ of lipid per $\mathrm{kg}$ of the rice flour.

Figure 3 also shows the effects of lipid reconstitution on the specific air volume. When the extracted lipid was added for reconstitution of the lipid-extracted rice flour, the specific air volume decrased to an extent a little less than the initial level of the rice flour, while the addition of the wheat lipid to the lipidextracted rice flour decreased the specific air volume, but not to the initial level of accompanying air of the rice flour.

\section{4) Combination of lipid extraction and drying}

When the strong wheat flour A was subjected to lipid extraction and then to drying, the greatest increase in the accompanying air was observed, as shown in Table I.

\section{5) Effect of oxidation}

The specific volumes of air accompanying the wheat flours and the rice flour were increased by oxidation with $1 \%$ benzoyl peroxide, as shown in Table I. The additional air accompanying the wheat flours was stable in

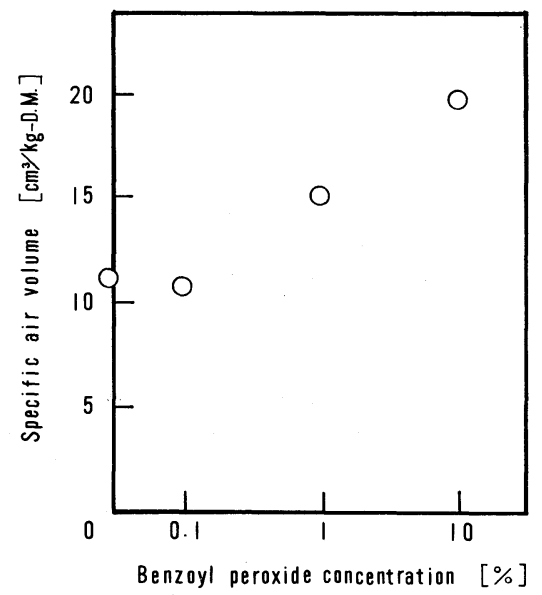

FIG. 5. Effect of Oxidation by Benzoyl Peroxide on the Specific Air Volume of Strong Wheat Flour A $\left(d_{\mathrm{p}}=74 \sim 125 \mu \mathrm{m}\right)$.

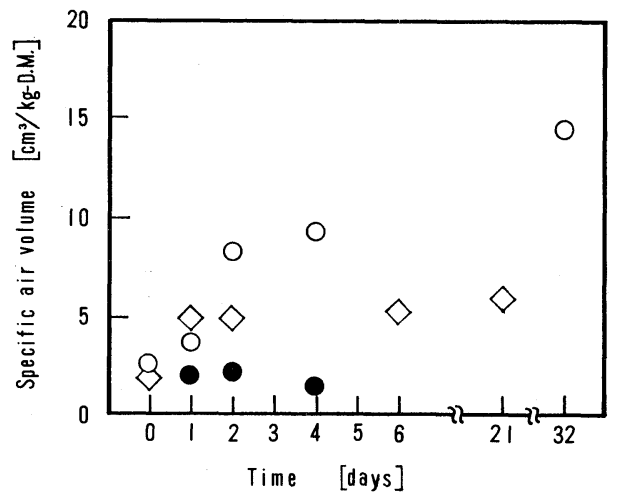

FIG. 6. Changes in Specific Air Volume during Aging $\left(d_{\mathrm{p}}=74 \sim 125 \mu \mathrm{m}\right)$.

○, No. 1. CW wheat flour; 1 , No. 1. CW wheat flour aged at $20 \mathrm{mmHg} ; \diamond$, non-glutinous rice flour.

The moisture content of the sample flours did not change significantly during the aging.

water, while the additional air accompanying the rice flour decreased, but not to the original level. With an increase in the benzoyl peroxide concentration the specific air volume increased, as shown in Fig. 5. When $10 \%$ of benzoyl peroxide was added to the strong wheat flour, however, the color of the flour changed to yellow. With $0.1 \%$ of benzoyl peroxide, this effect was not significant. The experiment in Fig. 5 was performed with the flour placed in an atmosphere of $58 \%$ relative humidity at $20^{\circ} \mathrm{C}$.

\section{6) Effect of aging}

As Fig. 6 shows, fresh milled flours were accompanied by only small amounts of air, but the accompanying air increased gradually during the aging of flours. However, if the wheat flour was aged under reduced pressure of $20 \mathrm{mmHg}$, the specific air volume didn't increase, as Fig. 6 shows.

\section{DISCUSSION}

Although various treatments are applied to wheat flours in food industries in order to improve their baking characteristics, measurements of changes in the amount of air accompanying flour particles have never been reported. The results of this paper, especially the 
data shown in Table 1, may constitute interesting information on the characteristics of flour particles, although part of the treatment mechanisms are not clear. The combination of lipid extraction and drying was the most effective for increasing the amount of accompanying air. It was of special interest that even for the rice flour, which held a very small amount of air, mostly in micropores inside particles, the accompanying air could be increased by some treatments up to the level in wheat flours. The treated rice flour holds a number of bubble nuclei, far more than the orifinal rice flour, that could greatly facilitate the easy and homogeneous expansion of the flour dough. The effects of an increase in the accompanying air of the rice flour on the extrusion of the flour dough will be dealt with elsewhere.

Acknowledgment. Part of this work was supported by a Grant-in-Aid for Scientific Research from the Ministry of Education, Science and Culture, Japan.

\section{REFERENCES}

1) C. S. Gaines and J. R. Donelson, Cereal Chem., 59, 378 (1982).

2) G. Huang, J. W. Finn and E. Varriano-Marston, Cereal Chem., 59, 496 (1982).

3) G. Huang, J. W. Finn and E. Varriano-Marston,
Cereal Chem., 59, 500 (1982).

4) D. W. Lillard, P. A. Seib and R. C. Hoseney, Cereal Chem., 59, 291 (1982).

5) R. L. Clements and J. R. Donelson, Cereal Chem., 59, 125 (1982).

6) C. S. Gaines and W. F. Kwolek, Cereal Chem., 59, 507 (1982).

7) G. Danno and R. C. Hoseney, Cereal Chem., 59, 202 (1982).

8) H. Salovaara, Cereal Chem., 59, 422 (1982).

9) R. L. Clements and J. R. Donelson, Cereal Chem., 59, 121 (1982).

10). S. Nagao and K. Tanaka, Nippon Shokuhin Kogyo Gakkaishi, 29, 185 (1982).

11) O. Paredes-Lopez and M. M. Covarrubias-Alvarez, J. Food Tech., 19, 225 (1984).

12) F. Macritchie, Cereal Chem., 58, 156 (1981).

13) O. K. Chung, Y. Pomeranz and K. F. Finney, Cereal Chem., 59, 14 (1982).

14) Y. Pomeranz, A. W. El-Baya, W. Seibel and H. Stephan, Cereal Chem., 61, 136 (1984).

15) Y. Shimiya and T. Yano, Agric. Biol. Chem., 51, 25 (1987).

16) N. A. Lange, "Lange's Handbook of Chemistry," ed. by J. A. Dean, Mcgraw-Hill Inc., New York, 1979, pp. $10 \sim 84$.

17) S. Henderson and S. W. Pixton, J. Sci. Food Agric., 32, 1145 (1981).

18) F. Macritchie and P. W. Gras, Cereal Chem., 50, 292 (1973).

19) M. Seguchi and J. Matsuki, Cereal Chem., 54, 918 (1977).

20) Nippon Mugirui-kenkyukai, "Komugiko," Uni-Art Co., Ltd., Tokyo, 1976, p. 450. 